\title{
Faecal lactoferrin and calprotectin in patients with Clostridium difficile infection: a case-control study
}

\author{
F. Barbut ${ }^{1,2,3} \cdot$ C. Gouot ${ }^{3} \cdot$ N. Lapidus ${ }^{4,5} \cdot$ L. Suzon ${ }^{1,2} \cdot$ R. Syed-Zaidi ${ }^{1,2} \cdot$ V. Lalande ${ }^{2,6}$. $^{1,2}$ \\ C. Eckert $^{1,2}$
}

\begin{abstract}
Calprotectin and lactoferrin are released by the gastrointestinal tract in response to infection and mucosal inflammation. Our objective was to assess the usefulness of quantifying faecal lactoferrin and calprotectin concentrations in Clostridium difficile infection (CDI) patients with or without free toxins in the stools. We conducted a single-centre 22month case-control study. Patients with a positive CDI diagnosis were compared to two control groups: group $1=$ diarrhoeic patients negative for $C$. difficile and matched (1:1) to CDI cases on the ward location and age, and group $2=$ diarrhoeic patients colonised with a non-toxigenic strain of $C$. difficile. Faecal lactoferrin and calprotectin concentrations in faeces were
\end{abstract}

This work was presented at the 26th European Congress of Clinical Microbiology and Infectious Diseases (ECCMID 2016), Amsterdam, the Netherlands, 9-11 April 2016.

F. Barbut

frederic.barbut@aphp.fr

1 National Reference Laboratory for Clostridium difficile, Hôpital Saint Antoine, AP-HP, 75012 Paris, France

2 UPMC Univ Paris 06, GRC n², Epidiff, Paris, France

3 Unité d'Hygiène et de Lutte contre les Infections Nosocomiales, Hôpital Saint-Antoine, AP-HP, Paris, France

4 Sorbonne Universités, UPMC Univ Paris 06, INSERM, Institut Pierre Louis d'Épidémiologie et de Santé Publique (IPLESP UMRS 1136), 75012 Paris, France

5 Département de Santé Publique, Hôpital Saint-Antoine, AP-HP, 75012 Paris, France

6 Département de Bactériologie, Hôpital Saint-Antoine, AP-HP, Paris, France determined for patients with CDI and controls. Of 135 patients with CDI, 87 (64.4\%) had a positive stool cytotoxicity assay (free toxin) and $48(35.6 \%)$ had a positive toxigenic culture without detectable toxins in the stools. The median lactoferrin values were $26.8 \mu \mathrm{g} / \mathrm{g}, 8.0 \mu \mathrm{g} / \mathrm{g}$ and $15.8 \mu \mathrm{g} / \mathrm{g}$ in CDI patients and groups 1 and 2, respectively. The median calprotectin values were $218.0 \mu \mathrm{g} / \mathrm{g}, 111.5 \mu \mathrm{g} / \mathrm{g}$ and $111.3 \mu \mathrm{g} / \mathrm{g}$, respectively. Among patients with CDI, faecal lactoferrin and calprotectin levels were higher in those with free toxins in their stools (39.2 vs. $10.2 \mu \mathrm{g} / \mathrm{g}, p=0.003$ and 274.0 vs. $166.0 \mu \mathrm{g} / \mathrm{g}, p=0.051$, respectively). Both faecal calprotectin and lactoferrin were higher in patients with CDI, especially in those with detectable toxin in faeces, suggesting a correlation between intestinal inflammation and toxins in stools.

\section{Introduction}

Clostridium difficile is recognised as the main causative agent responsible for nosocomial diarrhoea in adults [1]. The symptoms of $C$. difficile infections (CDI) range from self-limited diarrhoea to fulminant and sometimes fatal pseudomembranous colitis [2]. A study from the Netherlands found that patients with CDI had a higher 30-day mortality rate than controls who had diarrhoea but tested negative for $C$. difficile toxins (hazard ratio 1.6 ; 95\% confidence interval [CI] 0.9 2.8). This finding suggests that CDI, rather than diarrhoea per se, increased the mortality risk [3]. Major virulence factors include toxin A (tcdA) and toxin B (tcdB) that trigger intestinal inflammation and cell death [4]. Accurate and rapid diagnosis of CDI is essential for optimal treatment and prevention; however, reaching this goal continues to be challenging $[5,6]$.

Currently, the biological diagnosis of CDI is based on the detection in the stools of either free toxins (using enzyme immunoassays [EIAs] or a stool cytotoxicity assay) or a 
toxigenic strain (using toxigenic culture methods or nucleic acid amplification tests [NAATs]). However, as the EIAs for toxins lack sensitivity, the European Society of Clinical Microbiology and Infectious Diseases (ESCMID) guidelines recommend that they should not be used as standalone tests for the diagnosis of CDI [7]. Conversely, although NAATs are more sensitive, they are less specific for CDI compared with the direct detection of toxins in stools. Thus, while toxin tests may occasionally produce false-negatives in patients with $\mathrm{CDI}$, tests for toxigenic $C$. difficile may result in overdiagnosis and over-treatment. In particular, the new NAATs raise the crucial question of the clinical significance of the presence of a toxigenic strain without any free toxin in stools. Two large and recent studies from the UK and the USA showed that toxin positivity better correlates with clinical outcome and best defines true cases of CDI $[6,8,9]$.

Calprotectin and lactoferrin are two proteins produced by polymorphonuclear leucocytes and released by the gastrointestinal tract in response to infections and mucosal inflammation [10]. Measuring faecal concentrations of these proteins has been used to estimate the level of inflammation in diseases such as inflammatory bowel disease (IBD). Evidence regarding its use in the assessment of CDI remains limited [11-15].

The aim of this study was to evaluate whether faecal levels of calprotectin or lactoferrin could be used to distinguish patients with true CDI from those carrying a toxigenic strain.

\section{Materials and methods}

\section{Study population}

We conducted a case-control study at a single centre between 1 January 2014 and 31 October 2015. Adult in-patients with a positive diagnosis of CDI ( $\geq 3$ liquid stools per day plus a positive test for toxins and/or a toxigenic strain) were consecutively recruited and compared to two control groups identified within the same time frame: group 1 consisted of diarrhoeic patients who tested negative for $C$. difficile and matched (1:1) to CDI cases on the ward location and age group (18-45, 45-65 and $>65$ years); group 2 consisted of diarrhoeic patients with a nontoxigenic (NT) strain of $C$. difficile. Patients with digestive infections due to organisms other than $C$. difficile or with IBD were excluded from the study.

The study protocol was approved by the local Research Ethics Committee and presented to the Infection Control Committee. Information was given to the patients but informed consent was not required by the ethics committee.

\section{Clinical assessment}

For each patient included, their clinical chart was reviewed and the following data were recorded: age, gender, co- morbidities, Charlson score, number of stools on the day of the CDI diagnosis, clinical symptoms (abdominal pain, fever, bloating), white blood cell counts, serum albumin, creatinine and C-reactive protein (CRP) levels. The origin of diarrhoea (community-acquired or healthcare-associated) was defined according to the European Centre for Disease Prevention and Control (ECDC)/Centers for Disease Control and Prevention (CDC) criteria [16, 17]. The severity of CDI was defined using the criteria summarised in electronic supplementary Table S1 [18-22]. CDI was considered complicated when patients presented with septic shock, perforation, admission to the intensive care unit (ICU), colectomy or megacolon [23]. Mortality was assessed at days 10, 30 and 90.

\section{Laboratory assays}

Stool samples were tested for $C$. difficile within $48 \mathrm{~h}$ of collection. Three different strategies were used for each stool sample: (i) the stool cytotoxicity assay on cell culture, (ii) the toxigenic culture on selective medium and (iii) a two-step algorithm. For the quantification of calprotectin and lactoferrin, stool samples were frozen and stored at $-80{ }^{\circ} \mathrm{C}$ before use.

\section{Stool cytotoxicity assay (CTA)}

CTA was performed using MRC-5 cells. Fresh stool specimens were diluted in phosphate-buffered saline (PBS) (1:10 $[\mathrm{w} / \mathrm{v}])$ and centrifuged at $2500 \times \mathrm{g}$ for $30 \mathrm{~min}$. The supernatant was passed through a $0.45-\mu \mathrm{m}$ pore size filter and added to confluent monolayers of MRC-5 cells in 96-well microplates. The final stool dilution was 1:100. Plates were incubated at $37{ }^{\circ} \mathrm{C}$ in a $6.5 \% \mathrm{CO}_{2}$ atmosphere for $48 \mathrm{~h}$. Samples were considered positive if a characteristic cytopathic effect (cell rounding) was observed for at least $50 \%$ of the cells which could be neutralised with anti-Clostridium sordellii antiserum (obtained from M. R. Popoff, National Reference Center for Anaerobes, Pasteur Institute, Paris, France) [5].

\section{Toxigenic culture}

Toxigenic culture was performed with the selective chromogenic medium ChromID C. difficile (bioMérieux, Marcy l'Etoile, France). Plates were incubated for $48 \mathrm{~h}$ at $37^{\circ} \mathrm{C}$ in an anaerobic atmosphere. Black colonies or suspicious nonblack colonies (based on the morphological aspect) were analysed using matrix-assisted laser desorption/ionisation time-of-flight (MALDI-TOF) mass spectrometry (Bruker Daltonik, $\mathrm{GmbH})$. Clostridium difficile isolates were incubated in brain heart infusion broth for 5 days and the supernatant was tested using the CTA. 


\section{Two-step algorithm}

A first screening step detected the glutamate dehydrogenase (GDH) using the C. DIFF CHEK-60 assay (TechLab, Blacksburg, VA), according to the manufacturers' instructions. In a confirmatory step, positive stool samples were tested for the presence of the $t c d \mathrm{~B}$ gene using polymerase chain reaction (PCR) (Xpert $C$. difficile, Cepheid, Sunnyvale, CA).

\section{Faecal calprotectin and lactoferrin quantification}

Faecal calprotectin concentrations were determined using a quantitative immunoassay according to the manufacturers' instructions (Quantum Blue, Bühlmann). Briefly, faecal aliquots $(\approx 80 \mathrm{mg})$ were extracted using a faecal sample preparation kit (Bühlmann Smart-Prep). Extraction was performed in duplicate for each stool sample. Each sample was then diluted 1:10 with extraction buffer and centrifuged. The resulting supernatant was assayed using a lateral flow assay (Quantum Blue Calprotectin Extended quantitative lateral flow assay), with a range between 30 and $1000 \mu \mathrm{g} / \mathrm{g}$. For values exceeding $1000 \mu \mathrm{g} / \mathrm{g}$, the Quantum Blue Calprotectin High Range assay was used, with a range between 100 and $1800 \mu \mathrm{g} / \mathrm{g}$. Samples with values exceeding $1800 \mu \mathrm{g} / \mathrm{g}$ were further diluted 1:5 with Chase Buffer and re-tested according to the manufacturers' instructions. The final concentration for each stool sample was determined by averaging the two values measured using the Quantum Blue Calprotectin extended assay. When values exceeded $1000 \mu \mathrm{g} / \mathrm{g}$, the concentration measured using the High Range assay was acceptable.

Faecal lactoferrin concentrations were determined with a quantitative enzyme-linked immunosorbent assay (ELISA) according to the manufacturers' instructions (IBD-SCAN, TechLab, Blacksburg, VA). Briefly, $50 \mu \mathrm{L}$ of stool samples were diluted 1:100 and 1:1000. Diluted specimens and standards were transferred to microplate wells. The lactoferrin concentration was determined by plotting absorbance values on a curve generated by lactoferrin standards ranging from 6.25 to $100 \mathrm{ng} / \mathrm{mL}$. If both sample dilutions had absorbance readings greater than that recorded for the highest concentration of standard, the test was repeated using additional 1:10,000 dilutions. Conversely, any sample having an absorbance reading less than that recorded for the lowest concentration of standard was retested using a 1:10 dilution and, if found negative, recorded as $<1 \mu \mathrm{g} / \mathrm{g}$ wet weight. The final concentration for each stool sample was determined by averaging the two values recorded with the same dilution.

\section{Data analysis}

Statistical analyses were performed using R software version 3.1 (R Foundation for Statistical Computing, Vienna, Austria) and GraphPad Prism 5.04 (GraphPad Software, Inc., La Jolla,
CA). Patient demographic characteristics were described by their median and interquartile range (IQR) for quantitative variables and frequency for categorical variables. Quantitative and categorical variables were compared between cases and matched controls (group 1) with Wilcoxon signed-rank and McNemar tests and between cases and unmatched controls (group 2) with Mann-Whitney-Wilcoxon and Fisher exact tests. We plotted receiver operating characteristic (ROC) curves and estimated the area under curve (AUC) to assess the ability of faecal lactoferrin and calprotectin to distinguish patients with CDI from their matched controls, for both patients with and without free toxins in their stools. Covariates associated with CDI cases with and without detectable toxins were identified with univariate conditional logistic regression modelling and multivariate modelling, after adjustment for the main baseline confounders (age, gender and Charlson score). Normality of quantitative covariates was tested and $\log _{2}$-transformed when needed. Regression estimates for these covariates should, therefore, be interpreted as a variation per two-fold increase of the value. As lactoferrin and calprotectin quantification was left- and right-censored, we used values beyond these thresholds for the lower or upper limits of detection. A $p$-value of $<0.05$ was considered significant.

\section{Results}

A total of 135 patients with CDI ( 81 females and 54 males, median age 64 [IQR: 51-78]) were included: 87 (64.4\%) had a positive CTA (free toxin) and $48(35.6 \%)$ had a negative CTA (absence of detectable toxins in the stools) but a positive toxigenic culture or PCR result. Among patients without detectable toxins in the stools, one had a positive toxigenic culture and a negative PCR result, whereas three other patients had a negative toxigenic culture and a positive PCR result. Among the CDI cases, 113 (83.7\%) were primary episodes and 22 (16.3\%) were recurrences. Patients were hospitalised in medical wards ( $n=116 ; 85.9 \%)$, surgical wards $(n=9 ; 6.7 \%)$ or the ICU $(n=10 ; 7.4 \%)$. CDI cases were categorised as healthcareassociated $(n=115 ; 85.1 \%)$, community-acquired $(n=19$; $14.1 \%)$ or of indeterminate origin $(n=1 ; 0.7 \%)$. In the previous 3 months, 104 (77.0\%) patients had received antibiotic treatment. The frequency of moderate/severe cases ranged from $19.3 \%$ to $80.0 \%$, depending on the definition used (Table 1). There were five complicated cases (defined by septic shock, perforation, admission to the ICU, colectomy or megacolon; $3.7 \%)$. Six deaths (4.4\%) were CDI-related.

The median lactoferrin values were significantly higher in patients with CDI $(26.8 \mu \mathrm{g} / \mathrm{g}$; IQR: $4.5-79.8)$ than in the matched controls who were CDI-negative $(8.0 \mu \mathrm{g} / \mathrm{g}$, IQR: $2.1-$ 32.7) ( $p=0.0017$ ) (Table 1). Similarly, the median calprotectin values were higher in patients with CDI $(218.0 \mu \mathrm{g} / \mathrm{g}$, IQR: $67.2-$ 
Table 1 Comparison of Clostridium difficile infection (CDI) patients with their matched controls (group 1) and unmatched controls harbouring a nontoxigenic strain of $C$. difficile (group 2)

\begin{tabular}{|c|c|c|c|c|c|}
\hline \multirow{2}{*}{$\begin{array}{l}\text { Variables } \\
\text { Biological and clinical features }\end{array}$} & \multirow[t]{2}{*}{ CDI (cases) $(n=135)$} & \multicolumn{2}{|l|}{$\begin{array}{l}\text { Matched controls } \\
\text { (group 1) }(n=135)\end{array}$} & \multicolumn{2}{|c|}{$\begin{array}{l}\text { Unmatched controls with a } \\
\text { non-toxigenic } C \text {. difficile } \\
\text { strain (group 2) }(n=50)\end{array}$} \\
\hline & & & $p$-Value & & $\begin{array}{l}p \text {-Value } \\
\quad \text { (versus CDI cases) }\end{array}$ \\
\hline Age (years) & $64[51-78]$ & $63[49.5-73.5]$ & 0.1322 & $58[45.8-66.0]$ & 0.0136 \\
\hline Gender (female), $n(\%)$ & $81(60 \%)$ & $66(48.9 \%)$ & 0.0548 & $21(42.0 \%)$ & 0.0318 \\
\hline Charlson index & $2[2-3]$ & $2[2-3]$ & 0.1952 & $2[2-4]$ & 0.2396 \\
\hline Immunosuppression & $67(49.6 \%)$ & $76(56.3 \%)$ & 0.1172 & $40(80.0 \%)$ & 0.0002 \\
\hline No. of stools/day & $4[3-6]$ & $3[2-5]$ & 0.0019 & $3[2-4]$ & 0.0061 \\
\hline Temperature $\left({ }^{\circ} \mathrm{C}\right)$ & $37.3[37.1-38.2]$ & $37.2[37.0-37.95]$ & 0.1163 & $37.3[37.3-38.0]$ & 0.4421 \\
\hline Abdominal distension, $n(\%)$ & $24(17.8 \%)$ & $10(7.4 \%)$ & 0.0082 & $0(0.0 \%)$ & 0.0004 \\
\hline Rectal bleeding, $n(\%)$ & $5(3.7 \%)$ & $3(2.2 \%)$ & 0.4795 & $0(0.0 \%)$ & 0.3258 \\
\hline Abdominal pain, $n(\%)$ & $86(63.7 \%)$ & $63(46.7 \%)$ & 0.0019 & $25(50.0 \%)$ & 0.0950 \\
\hline Leucocytes $\left(/ \mathrm{mm}^{3}\right)$ & $7580[3105-14,250]$ & $7395[2482-10,430]$ & 0.0362 & $4560[2000-7572]$ & 0.0059 \\
\hline $\begin{array}{l}\text { Polynuclear neutrophil } \\
\text { count }\left(/ \mathrm{mm}^{3}\right)\end{array}$ & $7030[2510-13,790]$ & $5020[2100-7820]$ & 0.0016 & 3685 [2008-6002] & 0.0025 \\
\hline Creatinine $(\mu \mathrm{mol} / \mathrm{L})$ & $73[58.25-95]$ & $79[65-106.50]$ & 0.0102 & $77[56-104]$ & 0.7205 \\
\hline Albuminemia (mg/dL) & $32[26-35]$ & $32[26-36]$ & 0.1889 & $31(27-34]$ & 0.4580 \\
\hline C-reactive protein $(\mathrm{mg} / \mathrm{L})$ & $45[17-109.5]$ & 39 [16-104] & 0.6492 & $47[9-108]$ & 0.5394 \\
\hline Calprotectin $(\mu \mathrm{g} / \mathrm{g})$ & $218.0[67.2-795.5]$ & $111.5[34.8-374.5]$ & 0.0010 & $111.3[43.9-374.8]$ & 0.0113 \\
\hline Lactoferrin $(\mu \mathrm{g} / \mathrm{g})$ & $26.8[4.5-79.8]$ & $8.0[2.1-32.7]$ & 0.0017 & $15.9[2.5-51.6]$ & 0.0634 \\
\hline \multicolumn{6}{|l|}{ Outcome, $n(\%)$} \\
\hline Death at D10 & $5(3.7 \%)$ & $4(3.0 \%)$ & 0.7389 & $2(4.0 \%)$ & 1 \\
\hline Death at D30 & $18(14.5 \%)$ & $10(9.3 \%)$ & 0.2253 & $5(10.9 \%)$ & 0.6221 \\
\hline Death at D90 & $31(27.4 \%)$ & $15(15.6 \%)$ & 0.0343 & $8(19.6 \%)$ & 0.3064 \\
\hline \multicolumn{6}{|l|}{ Scores of diarrhoea severity, $n(\%)$} \\
\hline Surawicz et al. & & & 0.3173 & & 1 \\
\hline Non-severe & $67(80.7 \%)$ & $90(80.4 \%)$ & & $35(81.4 \%)$ & \\
\hline Severe & $16(19.3 \%)$ & $22(19.6 \%)$ & & $8(18.6 \%)$ & \\
\hline Zar et al. & & & 0.2498 & & 0.0402 \\
\hline Non-severe & $103(76.3 \%)$ & $110(81.5 \%)$ & & $45(90.0 \%)$ & \\
\hline Severe & $32(23.7 \%)$ & $25(18.5 \%)$ & & $5(10 \%)$ & \\
\hline Johnson et al. & & & 0.0006 & & 0.0042 \\
\hline Mild & $27(20.0 \%)$ & $51(38.1 \%)$ & & $21(42.0 \%)$ & \\
\hline Moderate/severe & $108(80.0 \%)$ & $83(61.9 \%)$ & & $29(58.0 \%)$ & \\
\hline Louie et al. & & & 0.0004 & & 0.0005 \\
\hline Mild & $64(47.4 \%)$ & $90(67.2 \%)$ & & $38(76.0 \%)$ & \\
\hline Moderate/severe & $71(52.6 \%)$ & $44(32.8 \%)$ & & $12(24 \%)$ & \\
\hline Cornely et al. & & & 0.8946 & & 0.1505 \\
\hline Non-severe & $88(65.7 \%)$ & $90(67.2 \%)$ & & $38(77.5 \%)$ & \\
\hline Severe & $46(34.3 \%)$ & $44(32.8 \%)$ & & $11(22.4 \%)$ & \\
\hline
\end{tabular}

795.5) than in the matched controls (111.5 $\mu \mathrm{g} / \mathrm{g}$, IQR: $34.8-$ $374.5, p=0.001)$. Forty-three patients had faecal calprotectin concentrations $<30 \mu \mathrm{g} / \mathrm{g}$ (the detection threshold) and nine had concentrations above $9000 \mu \mathrm{g} / \mathrm{g}$; for faecal lactoferrin, six patients had concentrations $<1 \mu \mathrm{g} / \mathrm{g}$ and three had levels $>950 \mu \mathrm{g} /$ g. Both markers were highly correlated (Spearman's correlation coefficient $0.76 ; 95 \%$ CI $0.71-0.81 ; p<0.0001)$. The median faecal lactoferrin and calprotectin levels were higher in patients with CDI and detectable toxins in stools compared to CDI patients without free toxin ( $39.0 \mu \mathrm{g} / \mathrm{g}$, IQR: $6.7-106.0 \mathrm{vs.} 10.2 \mu \mathrm{g} /$ g, IQR: 3.1-37.5, $p=0.003$ and $274.0 \mu \mathrm{g} / \mathrm{g}$, IQR: 85.8-1321.0 vs. $166.0 \mu \mathrm{g} / \mathrm{g}$, IQR: $47.0-535.0, p=0.051$, respectively). 
The calprotectin levels were significantly higher in patients with CDI than the 50 controls with a non-toxigenic strain of C. difficile (referred to as control group 2) $(218.0 \mu \mathrm{g} / \mathrm{g}$, IQR: 67.2-795.5 vs. $111.2 \mu \mathrm{g} / \mathrm{g}$, IQR: $43.9-374.8, p=0.011$ ). The lactoferrin levels were not significantly different between these groups $(26.8 \mu \mathrm{g} / \mathrm{g}$, IQR: $4.5-79.8$ vs. $15.9 \mu \mathrm{g} / \mathrm{g}$, IQR: $2.5-51.6, p=0.063)$.

Patients with or without detectable toxins were compared separately to their corresponding matched controls. The ROC curves indicated that the AUC varied between 0.59 (95\% CI $0.47-0.70$ ) and 0.67 (95\% CI 0.59-0.75) (Fig. 1). Using a univariate logistic regression model, the lactoferrin and calprotectin levels (expressed as $\log _{2}$ ) were significantly associated with CDI with detectable toxin but not with CDI without detectable toxin (estimates not reported here). Adjustments for age, gender and Charlson score did not provide significantly different results (Fig. 2, Table 2A and B).

We specifically examined the clinical data and outcome of CDI patients without detectable toxin in stools who displayed either high levels of faecal calprotectin $(>500 \mu \mathrm{g} / \mathrm{g}, n=13$ ) or lactoferrin $(>50 \mu \mathrm{g} / \mathrm{g}, n=10)$. Among the 15 patients, eight had both elevated faecal inflammatory markers. All patients except two $(86.7 \%, 13 / 15)$ were treated with oral vancomycin $(n=3)$, metronidazole $(n=9)$ or fidaxomicin $(n=1)$, and were considered clinically cured at day 10 .

\section{Discussion}

Calprotectin and lactoferrin are two proteins derived from polymorphonuclear neutrophils which are released by the gastrointestinal tract in response to infections and mucosal inflammation. As such, these markers are routinely used to monitor levels of inflammation in patients with IBD. It is proposed that, as CDI is histologically characterised by an infiltration of neutrophils, faecal lactoferrin or calprotectin may represent potential biomarkers for disease activity.

Using a case--control study including 135 patients with CDI, we have shown that both faecal calprotectin and lactoferrin significantly increased during CDI. These two markers were highly correlated with each other $(r=0.76)$, which is unsurprising considering their common cellular origin. These results are consistent with those published by Swale et al. [12], who also compared both markers in a cohort
Fig. 1 Receiver operating characteristic (ROC) curves of faecal calprotectin and lactoferrin for predicting Clostridium difficile infection (CDI) based on positive free toxin test (right side) or positive $C$. difficile toxin gene assay without detectable toxin (left side)
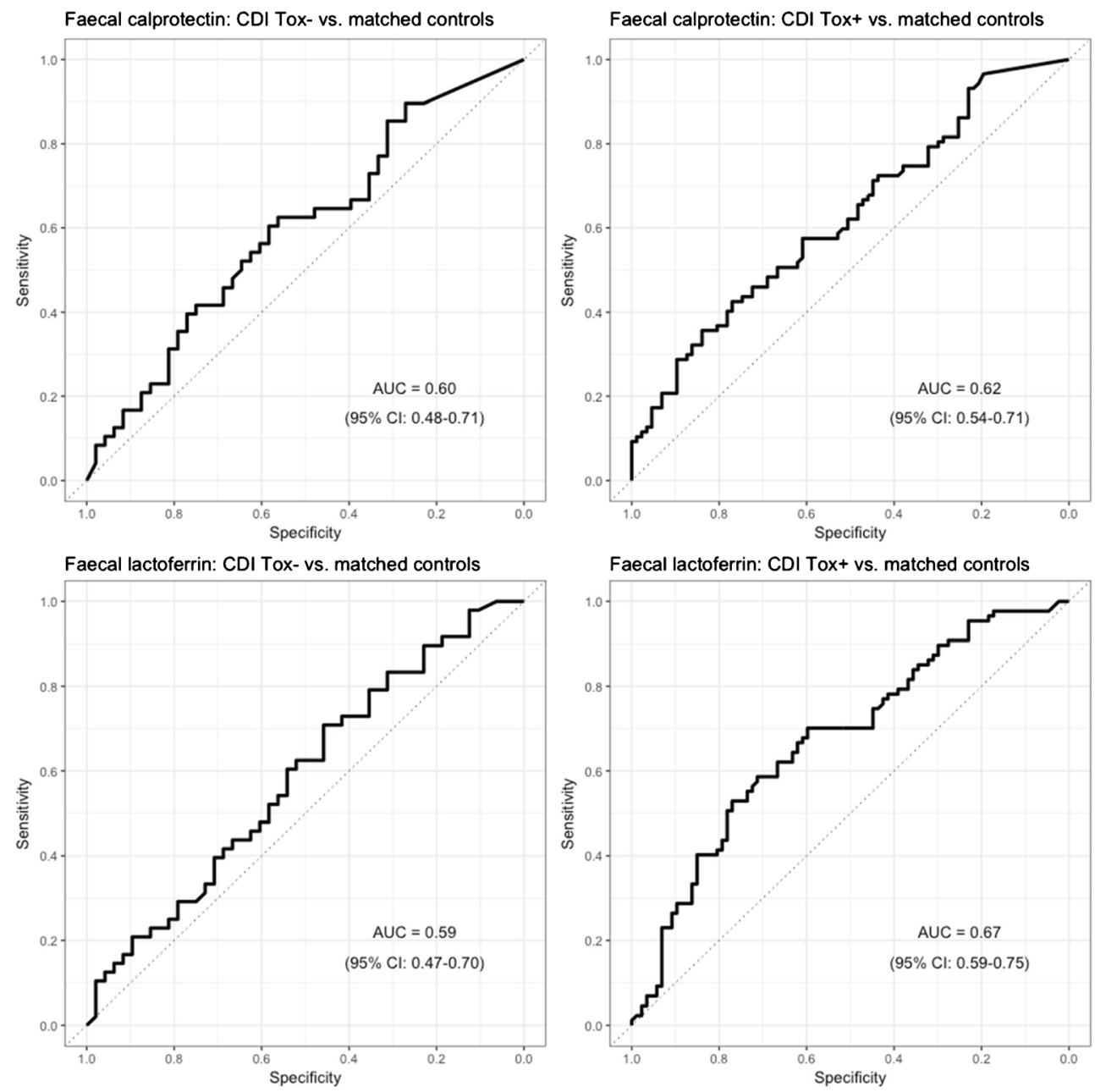

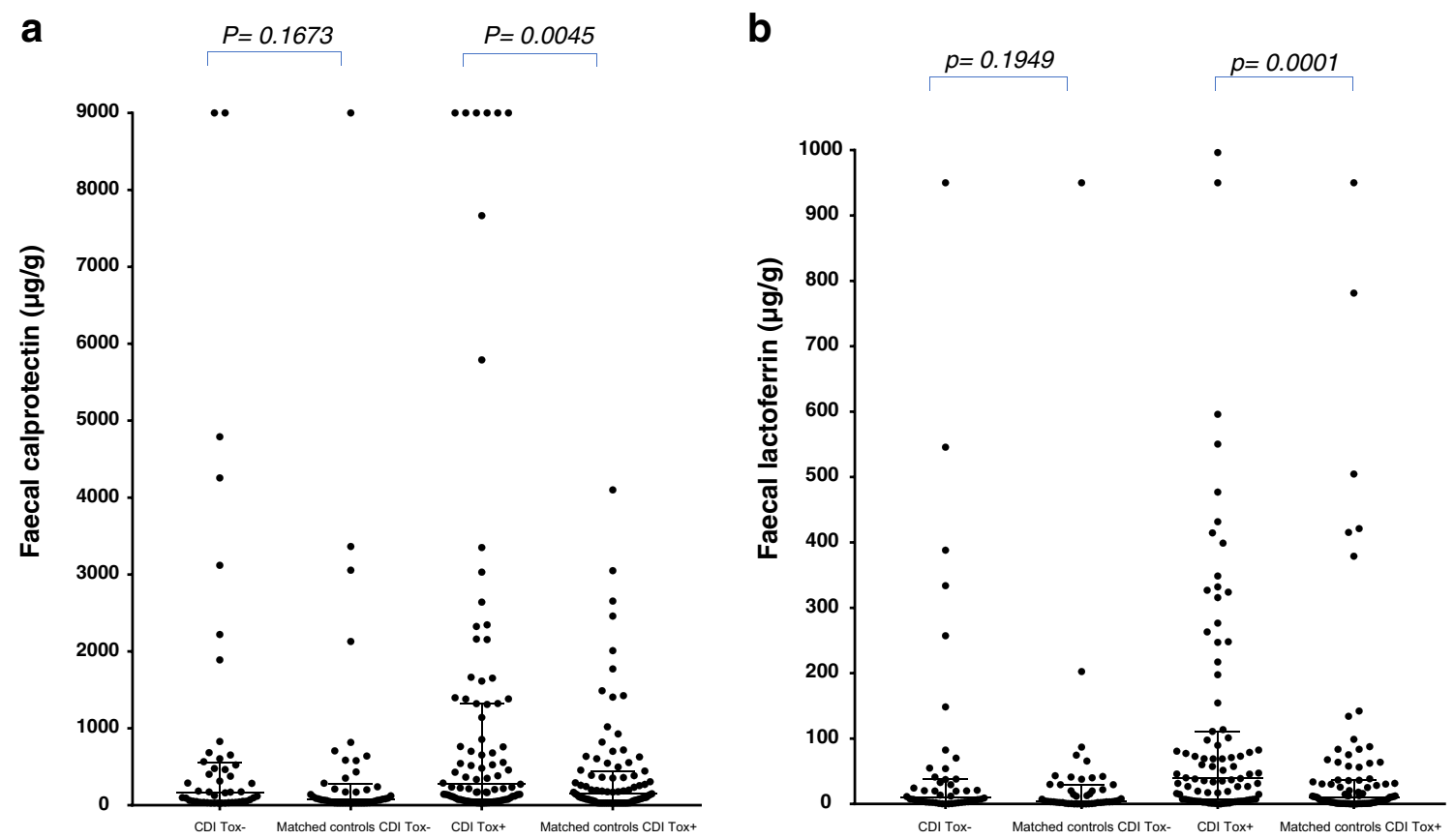

Fig. 2 Comparison of faecal calprotectin levels (a) and lactoferrin levels (b) in patients with CDI (stratified according to the presence or absence of detectable toxin) and their matched controls (the bars represent median values and their interquartile range)

Table 2 Comparison of CDI cases with (A) or without (B) detectable toxins in stools to their matched controls (multivariate logistic regression estimates adjusted for age, gender and Charlson score)

\begin{tabular}{|c|c|c|c|}
\hline \multicolumn{4}{|l|}{ A } \\
\hline Variables & OR & $95 \% \mathrm{CI}$ & $p$-Value \\
\hline Lactoferrin $\left(\log _{2}\right)$ & 1.244 & $1.097-1.410$ & 0.0007 \\
\hline Calprotectin $\left(\log _{2}\right)$ & 1.274 & $1.077-1.507$ & 0.0047 \\
\hline No. of stools & 1.101 & $0.984-1.231$ & 0.0923 \\
\hline Leucocytes $\left(\log _{2}\right)$ & 0.970 & $0.822-1.146$ & 0.7203 \\
\hline Death at D30 & 2.136 & $0.527-8.659$ & 0.2879 \\
\hline Death at $\mathrm{D} 90$ & 1.704 & $0.459-6.323$ & 0.4260 \\
\hline Severe diarrhoea (Surawicz et al.) & 0.495 & $0.136-1.807$ & 0.2875 \\
\hline Severe diarrhoea (Zar et al.) & 1.050 & $0.464-2.374$ & 0.9069 \\
\hline Moderate/severe diarrhoea (Johnson et al.) & 2.520 & $1.157-5.487$ & 0.0200 \\
\hline Moderate/severe diarrhoea (Louie et al.) & 1.795 & $0.817-3.943$ & 0.1455 \\
\hline Severe diarrhoea (Cornely et al.) & 0.868 & $0.457-1.652$ & 0.6673 \\
\hline \multicolumn{4}{|l|}{$\mathrm{B}$} \\
\hline Variables & OR & $95 \% \mathrm{CI}$ & $p$-Value \\
\hline Lactoferrin $\left(\log _{2}\right)$ & 1.116 & $0.968-1.287$ & 0.1303 \\
\hline Calprotectin $\left(\log _{2}\right)$ & 1.141 & $0.951-1.370$ & 0.1562 \\
\hline No. of stools & 1.157 & 0.9741 .374 & 0.0960 \\
\hline Leucocytes $\left(\log _{2}\right)$ & 0.943 & $0.748-1.189$ & 0.6200 \\
\hline Death at D30 & 1.434 & $0.302-6.814$ & 0.6500 \\
\hline Death at D90 & 5.905 & $1.212-28.767$ & 0.0200 \\
\hline Severe diarrhoea (Surawicz et al.) & 1.041 & $0.219-4.955$ & 0.9595 \\
\hline Severe diarrhoea (Zar et al.) & 4.949 & $0.551-44.444$ & 0.1534 \\
\hline Moderate/severe diarrhoea (Johnson et al.) & 3.504 & $1.125-10.917$ & 0.0305 \\
\hline Moderate/severe diarrhoea (Louie et al.) & 6.417 & $1.775-23.202$ & 0.0046 \\
\hline Severe diarrhoea (Cornely et al.) & 1.472 & $0.449-4.827$ & 0.5237 \\
\hline
\end{tabular}


of 162 patients and 52 non-matched controls with antibioticassociated diarrhoea [12]. Consistent with other studies, we observed a great variability of faecal lactoferrin and calprotectin levels, with a significant overlap between cases and controls $[14,23]$. This observation actually reduces the predictive accuracy of both markers for CDI and makes it difficult to determine an optimal cut-off value. However, the large inter-individual variability may be due, in part, to the over-diagnosis of CDI when tests for toxigenic $C$. difficile or NAATs are used. Interestingly, when the population with CDI was split into patients with a positive CTA (free toxin) and those positive for PCR or toxigenic culture but negative for the CTA, we found that levels of faecal calprotectin and lactoferrin remained significantly higher only in patients with free toxin compared to their controls. Similarly, the AUCs for both calprotectin and lactoferrin, although low, were slightly higher for CDI patients with free toxin compared to those who were positive for PCR or toxigenic culture but negative for the CTA. A similar observation was reported by LaSala et al., who found higher faecal lactoferrin levels in CDI patients with detectable toxin than in patients with a toxigenic strain without any detectable toxin in the faeces (median 80 [range: 3-124] $\mu \mathrm{g} / \mathrm{mL}$ vs. 24 [range: $4-160] \mu \mathrm{g} / \mathrm{mL}$, respectively) [14]. In another independent study, the median faecal calprotectin levels were higher in patients with a positive stool CTA than in those who were toxin gene positive but negative for the CTA assay $(336 \mu \mathrm{g} / \mathrm{g}$ [IQR: $208-536 \mu \mathrm{g} / \mathrm{g}$ ] vs. $249 \mu \mathrm{g} / \mathrm{g}$ [IQR: $155-498 \mu \mathrm{g} / \mathrm{g}$ ] [24]. These data are consistent with two recent studies, which suggest that the severity of CDI is greater in toxin-positive than in toxin-negative patients $[6,8]$. In a large study from the UK, Planche et al. $[6,9]$ found that patients with free toxins (detected by the stool CTA) had a significantly higher mortality rate within 6 months of diagnosis and higher mean white cells count than patients with positive NAATs and negative CTAs. Of note, a US study showed that virtually all CDI-related complications and deaths occurred in patients with positive toxin immunoassay test results [8]. In this study, patients with positive molecular and negative toxin immunoassay test results had comparable outcomes to patients without $C$. difficile. These data support the idea that C. difficile toxin is more closely linked to the infection than the toxin gene. The significance of the presence of toxigenic C. difficile strain without free toxin in a patient with diarrhoea remains debatable. This group of patients is likely to include patients with true CDI and patients carrying a toxigenic strain. Indeed, in our study, 15 patients from this group had a high level of either lactoferrin $(>50 \mu \mathrm{g} / \mathrm{g})$ or calprotectin $(>500 \mu \mathrm{g} /$ g). All except two were successfully treated for CDI for 10 to 14 days, suggesting that $C$. difficile might have been the cause of diarrhoea in these patients. This observation suggests that calprotectin or lactoferrin levels, in conjunction with clinical assessment, may help guide the decision to treat PCR-positive patients without detectable toxin in stools.
This study has several limitations. Firstly, it was performed in a single institution and the results might not be transposable to other healthcare settings with different patients and testing. Secondly, the number of patients is relatively low, despite representing one of the largest studies ever performed with these markers. Finally, we did not evaluate the usefulness of faecal lactoferrin and calprotectin for monitoring the efficacy of treatment or predicting the clinical outcome. However, we consider that this point deserves further study.

In summary, this case-control study showed that both faecal calprotectin and lactoferrin levels are higher in patients with CDI, especially those with detectable toxin in faeces, suggesting a correlation between intestinal inflammation and toxins in stools. In patients with a toxigenic strain without detectable toxin in stools, a high level of faecal lactoferrin or calprotectin could help guide the physician's decision to treat the patient.

\section{Compliance with ethical standards}

Funding/support The study was sponsored by the Association Robert Debré pour la Recherche Médicale. Astellas provided a research grant to the Association Robert Debré pour la Recherche Médicale based on the study protocol.

Astellas had no role in the study design and conduct, and was not involved in the data collection, data management, or data analysis and interpretation. Astellas provided editorial assistance with grammar and English language editing.

Conflict of interest Frédéric Barbut reports grants, personal fees and non-financial support from Astellas, personal fees from Pfizer, grants and personal fees from Sanofi Pasteur, grants and non-financial support from Anios, grants, personal fees and non-financial support from MSD, grants from bioMérieux, grants from Quidel Bühlmann, grants from Diasorin, grants from Cubist, grants from Biosynex and grants from GenePoc; Catherine Eckert reports non-financial support from Astellas and Mobidiag.

Ethical approval The study protocol was approved by the local Research Ethics Committee and presented to the Infection Control Committee.

Informed consent No.

\section{References}

1. Lessa FC, Mu Y, Bamberg WM, Beldavs ZG, Dumyati GK, Dunn JR, Farley MM, Holzbauer SM, Meek JI, Phipps EC, Wilson LE, Winston LG, Cohen JA, Limbago BM, Fridkin SK, Gerding DN, McDonald LC (2015) Burden of Clostridium difficile infection in the United States. N Engl J Med 372(9):825-834

2. Bartlett JG (2006) Narrative review: the new epidemic of Clostridium difficile-associated enteric disease. Ann Intern Med 145(10):758-764

3. Hensgens MP, Dekkers OM, Goorhuis A, LeCessie S, Kuijper EJ (2014) Predicting a complicated course of Clostridium difficile infection at the bedside. Clin Microbiol Infect 20(5):O301-O308

4. Leffler DA, Lamont JT (2015) Clostridium difficile infection. N Engl J Med 373(3):287-288 
5. Barbut F, Surgers L, Eckert C, Visseaux B, Cuingnet M, Mesquita C, Pradier N, Thiriez A, Ait-Ammar N, Aifaoui A, Grandsire E, Lalande V (2014) Does a rapid diagnosis of Clostridium difficile infection impact on quality of patient management? Clin Microbiol Infect 20(2):136-144

6. Davies KA, Longshaw CM, Davis GL, Bouza E, Barbut F, Barna Z, Delmée M, Fitzpatrick F, Ivanova K, Kuijper E, Macovei IS, Mentula S, Mastrantonio P, von Müller L, Oleastro M, Petinaki E, Pituch H, Norén T, Nováková E, Nyč O, Rupnik M, Schmid D, Wilcox MH (2014) Underdiagnosis of Clostridium difficile across Europe: the European, multicentre, prospective, biannual, pointprevalence study of Clostridium difficile infection in hospitalised patients with diarrhoea (EUCLID). Lancet Infect Dis 14(12): 1208-1219

7. Crobach MJ, Planche T, Eckert C, Barbut F, Terveer EM, Dekkers OM, Wilcox MH, Kuijper EJ (2016) European Society of Clinical Microbiology and Infectious Diseases: update of the diagnostic guidance document for Clostridium difficile infection. Clin Microbiol Infect 22(Suppl 4):S63-S81

8. Polage CR, Gyorke CE, Kennedy MA, Leslie JL, Chin DL, Wang S, Nguyen HH, Huang B, Tang YW, Lee LW, Kim K, Taylor S, Romano PS, Panacek EA, Goodell PB, Solnick JV, Cohen SH (2015) Overdiagnosis of Clostridium difficile infection in the molecular test era. JAMA Intern Med 175(11):1792-1801

9. Planche T, Wilcox M, Walker AS (2015) Fecal-free toxin detection remains the best way to detect Clostridium difficile infection. Clin Infect Dis 61(7):1210-1211

10. Langhorst $\mathrm{J}$, Boone $\mathrm{J}$ (2012) Fecal lactoferrin as a noninvasive biomarker in inflammatory bowel diseases. Drugs Today (Barc) 48(2):149-161

11. Boone JH, Archbald-Pannone LR, Wickham KN, Carman RJ, Guerrant RL, Franck CT, Lyerly DM (2014) Ribotype 027 Clostridium difficile infections with measurable stool toxin have increased lactoferrin and are associated with a higher mortality. Eur J Clin Microbiol Infect Dis 33(6):1045-1051

12. Swale A, Miyajima F, Roberts P, Hall A, Little M, Beadsworth MB, Beeching NJ, Kolamunnage-Dona R, Parry CM, Pirmohamed M (2014) Calprotectin and lactoferrin faecal levels in patients with Clostridium difficile infection (CDI): a prospective cohort study. PLoS One 9(8):e106118

13. Popiel KY, Gheorghe R, Eastmond J, Miller MA (2015) Usefulness of adjunctive fecal calprotectin and serum Procalcitonin in individuals positive for Clostridium difficile toxin gene by PCR assay. J Clin Microbiol 53(11):3667-3669

14. LaSala PR, Ekhmimi T, Hill AK, Farooqi I, Perrotta PL (2013) Quantitative fecal lactoferrin in toxin-positive and toxin-negative Clostridium difficile specimens. J Clin Microbiol 51(1):311-313
15. El Feghaly RE, Stauber JL, Deych E, Gonzalez C, Tarr PI, Haslam DB (2013) Markers of intestinal inflammation, not bacterial burden, correlate with clinical outcomes in Clostridium difficile infection. Clin Infect Dis 56(12):1713-1721

16. Kuijper EJ, Coignard B, Tüll P; ESCMID Study Group for Clostridium difficile; EU Member States; European Centre for Disease Prevention and Control (2006) Emergence of Clostridium difficile-associated disease in North America and Europe. Clin Microbiol Infect 12(Suppl 6):2-18

17. McDonald LC, Coignard B, Dubberke E, Song X, Horan T, Kutty PK; Ad Hoc Clostridium difficile Surveillance Working Group (2007) Recommendations for surveillance of Clostridium difficileassociated disease. Infect Control Hosp Epidemiol 28(2):140-145

18. Johnson S, Louie TJ, Gerding DN, Cornely OA, Chasan-Taber S, Fitts D, Gelone SP, Broom C, Davidson DM; Polymer Alternative for CDI Treatment (PACT) investigators (2014) Vancomycin, metronidazole, or tolevamer for Clostridium difficile infection: results from two multinational, randomized, controlled trials. Clin Infect Dis 59(3):345-354

19. Cornely OA, Crook DW, Esposito R, Poirier A, Somero MS, Weiss K, Sears P, Gorbach S; OPT-80-004 Clinical Study Group (2012) Fidaxomicin versus vancomycin for infection with Clostridium difficile in Europe, Canada, and the USA: a double-blind, non-inferiority, randomised controlled trial. Lancet Infect Dis 12(4):281-289

20. Louie TJ, Miller MA, Mullane KM, Weiss K, Lentnek A, Golan Y, Gorbach S, Sears P, Shue YK; OPT-80-003 Clinical Study Group (2011) Fidaxomicin versus vancomycin for Clostridium difficile infection. N Engl J Med 364(5):422-431

21. Zar FA, Bakkanagari SR, Moorthi KM, Davis MB (2007) A comparison of vancomycin and metronidazole for the treatment of Clostridium difficile-associated diarrhea, stratified by disease severity. Clin Infect Dis 45(3):302-307

22. Surawicz CM, Brandt LJ, Binion DG, Ananthakrishnan AN, Curry SR, Gilligan PH, McFarland LV, Mellow M, Zuckerbraun BS (2013) Guidelines for diagnosis, treatment, and prevention of Clostridium difficile infections. Am J Gastroenterol 108(4):478-498

23. Cohen SH, Gerding DN, Johnson S, Kelly CP, Loo VG, McDonald LC, Pepin J, Wilcox MH; Society for Healthcare Epidemiology of America; Infectious Diseases Society of America (2010) Clinical practice guidelines for Clostridium difficile infection in adults: 2010 update by the society for healthcare epidemiology of America (SHEA) and the infectious diseases society of America (IDSA). Infect Control Hosp Epidemiol 31(5):431-455

24. Whitehead SJ, Shipman KE, Cooper M, Ford C, Gama R (2014) Is there any value in measuring faecal calprotectin in Clostridium difficile positive faecal samples? J Med Microbiol 63(Pt 4):590-593 